Clinical Assistantships: Two clinical assistants per calendar month (men only) will be appointed at the Lambeth Hospilal. Daily attendance 10-1 and 2-5. Fee $£ 55$ s. per month.

Rota of Teachers: Details of the clinics available every day are given in the Supplement. Fee 5s. per clinic.

\title{
SPECIAL ANNOUNCEMENTS.
}

The main Course of the Institute of Medical Psychology, covering one year's work, begins on October 2, 1933. There are two groups $(a)$ for those who can attend for only three hours twice a week, and $(b)$ for those who, wishing to specialize, can give a minimum of twelve hours weekly, attending on three days.

An innovation this year will be the Systematic Lectures, once a week, which may be attended by Post-Graduates on payment of a fee of $5 \mathrm{~s}$.

Applications for the Course must be received by September 18, 1933. Further information is available either from the Fellowship of Medicine, or from the Institute of Medical Psychology, 6, Torrington Place, London, W.C. 1.

A Guide Book, giving details of how to reach the various London Hospitals by tube, tram, or 'bus, can be obtained from the Fellowship. Price 6d. (Members and Associates, 3d.).

\section{THE LEGAL PITFALLS OF THE SURGEON.'}

\section{BY DEREK HARCOURT KITCHIN, Of Gray's Inn, Barrister-at-Law, Fellow of the Roval Society of Medicine.}

BROADI.Y speaking, the legal pitfalls of the surgeon can be classified under quite a few heads. These are :

(i) Unlawful operations.

(ii) Failure to get the patient's consent.

(iii) Negligence : which means not using enough care and skill to satisfy a jury.

(iv) Being let down by other people.

Most pitfalls take the form of a civil action for damages by an aggrieved patient. In some cases, however, the surgeon may find himself in the dock charged with a criminal offence. His criminal liability is based on the old law prohibiting "mayhem." To maim a man was to do anything to him, whether he consented or not, which might

1 Address to the Fellowship of Medicine Post-Graduate Course held at the Seamen's Hospital, Albert Dock, June 11, 1933. 
make him less efficient as a soldier. This doctrine has broadened out until now-a-days it is an offence to cause grievous bodily harm to anyone, man or woman, old or young. The essence of the offence is not that it injures the person, but that it is against the interests of the State. The State is vitally interested in the well-being of each of its citizens, and it is an offence against public policy to impair that well-being. Because the offence is against the State, it cannot be justified by the consent of the injured person.

Bodily harm, to be grievous within the meaning of the law, need not be dangerous or even permanent, but is of a kind which seriously interferes with health or comfort. Most surgical work causes grievous bodily harm as the law understands it. Prima facie, therefore, every surgical operation of any gravity is an offence against the law, just as killing a man or woman is prima facie an offence against the law.

In certain circumstances it may be excusable to kill a man-for instance, in genuine self-defence-and the killer would not be punished; but he would be prosecuted and required to prove that his action was excusable. To such an extent does the law trust the surgeon that it assumes as a rule that every operation he performs has the therapeutic justification that makes his "offence" excusable. It does not, therefore, require him to supply evidence for the therapeutic necessity of every laparatomy! Nevertheless, an aggrieved patient may always prosecute a surgeon before a magistrate for the criminal offence of maiming him, and the surgeon would have to produce his proof that the procedure had been "excusable" on medical grounds. It would not be sufficient for him to prove that the patient had agreed to the operation, for consent does not justify the infliction of grievous bodily harm.

It is fairly certain that a surgeon may not sterilize a man, and possible that he may not sterilize a woman, for the sole reason that the patient wishes to avoid having children. The law considers it to be in the interest of the State that every citizen shall be able to reproduce, regardless of his or her fitness as a parent, and until this axiom is modified, voluntary sterilization will remain illegal. A surgeon who is asked to perform a sterilizing operation in the interests of the patient's health should satisfy himself that health would be seriously endangered if he did not do it, or he will risk a criminal prosecution. If something goes wrong and the patient dies, he will be tried for manslaughter. If the wife or husband is aggrieved, he is in danger of being prosecuted at their instance.

Similarly, it is a felony to cause abortion, and the surgeon who terminates pregnancy is only within the law if he has reason to believe that the patient will suffer damage to health if the child goes to term. All kinds of pressure are put upon gynæcologists to empty the uterus when the patient is for some reason unwilling to bear a child, and if he does not keep his head he may involve himself in serious trouble. The indications on which it is justifiable to terminate pregnancy have been exhaustively debated from time to time and can be found in text-books and files of journals. A precaution he should never omit is to obtain a good second opinion.

These are examples of the way in which a surgeon may come to appear in court as a criminal. In the remaining examples $I$ am going to put before you he would appear only as the defendant to a civil action. 1 do not propose to deal with criminal negligence, because to subject a surgeon to criminal liability negligence must be so gross and disgraceful that it is almost unknown among the profession. 


\section{Failure to Get the Patient's Consent.}

There is a dangerous group of pitfalls round the rule that the surgeon, before he operates, must have the consent of his patient. If he performs an operation without consent, or does more than the patient has authorized, or something different, the patient may bring a civil action against him and obtain heavy damages. In emergency the law will imply consent. For instance, if during an operation the surgeon finds that he must take certain steps in order to save life, he cannot be blamed for doing his best for the patient. It has been held that if, in order to save life, the surgeon removes some organ or limb and the patient is thereby injured, the patient can only get damages if he can prove that he expressly forbade the surgeon to remove that organ or limb, or that the operation was performed negligently. If a patient is brought into the casualty department unconscious, and some operation is necessary to save his life, he cannot give consent himself and, if a relative is available, the surgeon should obtain the relative's consent. Usually there is no one to ask, and the question arises whether, if the surgeon operates, the patient can afterwards obtain damages for assault and battery. The Court would probably ask whether the operation had been performed with due skill and care, and whether no more had been done than was reasonable. If these questions were answered satisfactorily, I do not think that the patient could get damages. But if the operation was unnecessary or could reasonably have been postponed until the patient recovered consciousness, the jury might find that the patient had suffered a wrong for which damages should be given.

When the patient is a child, the law requires the consent of the parent or guardian.

Most disputes about consent arise when a surgeon has taken out the uterus or both ovaries. The vast majority of hospital patients are perfectly content to let the surgeon decide for them and to believe that he has done his best, but when a patient finds that she cannot have any children she is apt to feel aggrieved, especially when her husband is angry and disappointed. It is possible that pressure is put on her by her relations and neighbours to go to law. The classical case of this kind is Beatty v. Cullingworth, which was tried in November, 1896.' Miss Beatty was a hospital nurse who came under surgical care for disease of the ovaries. Mr. Cullingworth diagnosed an inflamed cyst of the right ovary and could not say what the state of the left ovary was. The patient said that she was about to be engaged and that the operation was very important to her, and that she would not have it if there was any doubt about the second ovary. $\mathrm{Mr}$. Cullingworth refused to promise not to remove the second ovary. When Miss Beatty came into the theatre she said: "If you find both ovaries diseased, you must remove neither." Mr. Cullingworth replied, "You must really leave that to me, nurse. I know your wishes ; you may be sure that I shall not remove anything that I can help." She made no reply, but got on the table and took the anæsthetic. When the abdomen was opened, Mr. Cullingworth took out the right ovary, which was badly diseased, and found that the left ovary was diseased also. He first tried to treat the cyst by puncture and then by dissection, but found that he could not remove the cyst and at the same time leave a portion of the ovary, and so he removed the ovary.

Next day the patient abused him in the most violent terms and said he had acted

' The Times, November 17 and 18, 1896 ; Trans. Med.-Leg. Soc.. 1909, vi, 132. 
against her express instructions. She brought an action against him, but the jury stopped the case after hearing Mr. Cullingworth's evidence. Mr. Justice Hawkins, in summing up, said that if a medical man with a desire to do his best for his patient undertook an operation, it was a humane thing for him to do everything in his power to remove the mischief, provided that he had no absolutely definite instructions not to operate. "Would any surgeon," he asked, " undertake an operation fettered by such a condition as the one which the plaintiff suggested-namely, that if the operation was, in the surgeon's opinion, absolutely necessary, still he should not perform it if he found that there was a little more disease than he had supposed ?" The jury found a verdict for Mr. Cullingworth, and expressed the unanimous opinion that the action should never have been brought.

On this account of the facts $\mathrm{Mr}$. Cullingworth seems to have been rather lucky. Not only had he obtained no consent, but the patient had several times given him instructions which sounded very like a prohibition against removing both ovaries. The Court was probably much influenced by evidence that suggested that Miss Beatty had a somewhat unstable temperament, and by Mr. Cullingworth's opinion that her instructions showed that she was not in a fit state of mind to appreciate what she was saying. The Court interpreted as consent Miss Beatty's action in getting on the table after Mr. Cullingworth had told her that she must leave the decision to him. Some of the evidence suggested that she could not have had children even if the ovary had been left. One reason for her great objection to losing both was that, as a Roman Catholic, she believed that if she could not have children she ought not to marry. She lost her appeal, and was refused permission to go to the House of Lords as a poor person.

In a recent case a surgeon and a hospital were sued together: Cull v. The Royal? Surrey County Hospital and Butler. ${ }^{1}$ Mrs. Cull had had epileptic fits at long intervals. She became pregnant of her fourth child and, the second and third having died young, she and her husband were anxious to have a live child. She went to the hospital and Mr. Butler, the honorary surgeon, advised removal of the uterus because the pregnancy had caused the epileptic condition to become much worse. The husband and wife consulted their general practitioner and decided on curettage. The patient went back to hospital and the general practitioner wrote to the hospital informing it that she had decided not to undergo hysterectomy. This letter was filed with the "In-Patient's Letter" and Mr. Butler never saw it. At the operation he removed the uterus. The jury found that the hospital authorities had been negligent and assessed the damages at $£ \mathrm{I} 20$. The surgeon got off with a farthing damages, as he could not by any means have known of the letter. If you ask why he had to pay even nominal damages, I think the answer is that it is not enough for a surgeon to have no refusal; he must have actual consent.

The moral of these cases, and of many others like them, is that a surgeon should always be careful to secure written consent from the patient for the operation he intends to do. He must explain in simple language what he intends to do and the possibilities involved. He should, if anything, be more careful than usual when the operation is a sterilizing one. Oral consent cannot be really safe. Although a witness, and better still two witnesses, may prove that a patient gave consent, yet actions may be brought years

'The Lancet, 1932, i., 1377 ; British Medical Journal, 1932, i, 1195. 
after the operation, when memories are vague and witnesses may be dead or untraceable. One of the Protection Associations has devised forms which it recommends its members to use :-

"I .... of .... hereby consent to undergo the operation of . . . and/or such further or alternative operative measures as may be found to be necessary during the course of such operation."

(The latter part may be struck out if it is clearly not applicable.)

For sterilizing operations on women it recommends the alternative formula :-

"I ... . of .... hereby consent to undergo the operation of .... the effect and nature of which has been explained to me.

and

"I . . . of . . . . the husband of the above-named . . . hereby also consent to such operation."

It is not necessary in law for a husband to consent to an operation on his wife, provided that the wife herself consents, but the form is used to save dispute afterwards.

It is not advisable to use a form which is too comprehensive and which appears to give the surgeon an absolutely free hand. A jury may be much influenced in assessing damages if it believes that a surgeon has taken advantage of his carte blanche.

\section{Negligence.}

In ordinary language, negligence implies carelessly omitting to do something one ought to do. In law it is much wider, for it is the breach of a duty not only to take care but to use a reasonable degree of skill. If a man does not possess the skill necessary for a given task, in the eyes of the law he should not take it on except in an emergency. The law requires a surgeon to exercise a reasonable degree of care and a reasonable degree of skill. It does not define what that degree is ; in every case the jury has to decide whether, on the evidence, the surgeon has in fact used a degree of care and skill which is reasonable considering all the circumstances. The surgeon is not required in every case to manifest the highest degree of skill or an ideai degree of care ; the degree must be reasonable. Probably the jury would require much the same degree of care from every surgeon, and a very high degree, but the degree of skill required of him will vary with the kind of practice he is doing and what he holds himself out to possess. A general practitioner who practises surgery as part of his work, and is perhaps honorary surgeon at a cottage hospital, will not be expected to manifest the skill of the man who puts up his plate in a large town and specialises in surgery.

These are the legal rules, but as the jury has in every case to decide on whether the surgeon has been negligent, it follows that the result is always much in doubt. The pitfalls in this branch of the law are so numerous that they can hardly be counted, and most of them cannot be avoided even by the most scrupulous care and the most exceptional skill. It would be possible to multiply instances.

Last year Mr. Hey Groves ' had to defend an action for negligence because he encased a broken leg in plaster, and a cut in the heel became septic, so that the leg had to be amputated. The patient's advisers maintained that Mr. Hey Groves ought to have

1 Russell \%. Hay Groves and Lancaster. British Medical Journal, 1932, i, 1152, 1197. 
left a window over this cut. Many first-class surgeons, including Sir Robert Jones, testified that to do so would have been bad practice, and the jury found a verdict for the surgeon. Other men, however, though equally blameless, have not been so fortunate.

Volkmann's Ischæmic Contracture.-One of the bugbears of surgical practice is Volkmann's ischæmic contracture. Everyone knows that it is possible to produce this complication by bad bandaging and failure to watch for its early signs, but it is fairly generally admitted that in certain cases the deformity may appear despite every care. To convince a jury that this is so is not easy.

The case of Tyndall $v$. Alcock 1 was tried by Mr. Justice Shearman at the Bristol Assizes in 1927. It caused a tremendous amount of discussion at the time in the medical press. A little girl of 8 on her summer holiday fell off a donkey on the sands and broke the lower end of her humerus. She was seen at once; there was slight swelling and the broken ends were injuring the tissues. Mr. Alcock reduced the fracture, got the ends into alignment, suspended the arm from the shoulder and had an X-ray taken. The case is conspicuous for the meticulous care and consideration which he gave to the patient at every stage. He took her to hospital in his own car, gave careful instructions for watching the circulation in the arm and kept a careful watch himself. The next day there was slight swelling, and he loosened the bandages. Four or five days later he noticed slight discoloration; he took off the bandages and the sling, but Volkmann's ischæmic contracture had already set in and the arm was crippled. Unfortunately the little girl was a very promising piano player.

It appeared in the evidence that there was not a single fact on which anyone could have called Mr. Alcock negligent. He knew that the fracture was slightly over-reduced, but he thought this was advisable, as it involved less interference with the blood-vessels. $\mathrm{Mr}$. Hey Groves said that Mr. Alcock had adopted the proper course of treatment, and could find no fault with it. Nevertheless, the jury awarded $£ 2,000$ damages to the child and $f_{15} \mathrm{O}$ to the mother. Why? Possibly because they felt deeply, as everyone did, that it was a shocking bit of bad luck for the little girl, and they wanted her to have compensation. They were set certain questions to answer, and the way in which they first answered them showed that they did not think Mr. Alcock had been negligent, but they thought the little girl ought to be compensated for the loss of her piano-playing. When the judge explained to them that they could not give her compensation without finding $\mathrm{Mr}$. Alcock negligent, they found him negligent.

The case went to appeal, but in this country the findings of a jury on fact have a sacred character which no one, not even the House of Lords, can overrule. The Court of Appeal can only reverse a jury's finding if it thinks there has been absolutely no evidence to support it. In this case, as in nearly every case, there was some evidence, and the appeal was dismissed. Lord Justice Scrutton remarked that he thought a jury was rarely a suitable tribunal to try a case which involved a right differentiation between what was an error of judgment, which is not actionable, and a departure from the required degree of skill, which is. Lord Justice Sankey (as he then was) disagreed, and said that a jury was more likely to come to the right conclusion than a committee of experts. Lord Justice Romer observed, somewhat ironically, that Mr. Alcock must get 
such consolation as he could out of the fact that trial by jury was the foundation of his liberties!

This case shows what a surgeon is up against. The right answer to the jury, which unfortunately the judge could not give, was that given by a county court judge in very similar circumstances. In this court there were eight jurymen, and the foreman announced: "We find that the defendant was not guilty of negligence, but we think the plaintiff ought to have $£ 24$ compensation." "Very well, gentlemen," said the judge, "that will be $f_{3}$ from each of you!"

Idiosyncrasy.-Mishaps sometimes take place through some special sensitivity or idiosyncrasy in a patient. One of the commonest of these conditions is an abnormal liability to sepsis or inflammation. Mr. Hey Groves's patient was obviously one of these people ; in the very large majority of patients' injuries such a cut would have healed' inside the plaster. In a case called Murdock $v$. Holmes and Taylor, ${ }^{1}$ which was tried at the Leicester Assizes in 1925, the patient Murdock had a prolonged laparotomy for intestinal obstruction. The anæsthetic was two parts of ether to one of chloroform, given on an open mask. On the day after the operation he had a violent pain in his. left eye with acute inflammation and swelling of the epithelium of the cornea. A dense scar formed over the middle of the cornea and the patient lost the sight of that eye. An ophthalmologist gave evidence that the condition was not inconsistent with some anæsthetic having dropped into the eye, and it was proved that the Gamgee pad had twice got so wet with the anæsthetic that the anæsthetist had changed it. On the other hand, the patient was proved to have been in a highly toxic state in which he was abnormally sensitive to poisonous substances. Some witnesses said that liquidanæesthetic will not hurt a normal eye much, and that in a patient whose general condition was so bad the injury might have been due to the vapour alone, which no one can prevent from reaching the eye. The jury disagreed and were discharged.

It is worth noticing that the surgeon was sued as well as the anæsthetist. The best legal authority I have consulted tells me emphatically that the surgeon cannot be held responsible for work that is peculiarly in the anæsthetist's province, as the anæsthetist is an independent and skilled person and the surgeon has quite enough to do himself. The surgeon might possibly be held liable in a case like this if he had known or had good reason to believe that the patient was unduly sensitive to the anæsthetic ; or if he had had the duty of selecting the anæsthetist, and had selected one whose competence he had reason to doubt. But he cannot be held liable for a careless action by an anæsthetist whom he believes to be competent. In any case, neither surgeon nor anæsthetist can be blamed for an idiosyncrasy in the patient of which they have had no notice.

Patients sometimes become very ill with the ordinary dose of cocaine and other local anæsthetics. As a surgeon can ascertain this idiosyncrasy if he wishes, he might be held liable if a patient suffered severe injury from the local anæsthetic. Some surgeons advise a routine test with a drop of the preparation, and I certainly think that this is a wise precaution. 
Novel Treatments.-Sometimes it is necessary to carry out for the first time a newly-invented form of treatment. In olden days this used to be more dangerous legally than it is now. In $1767^{1}$ a very distinguished surgeon called Baker, who had been first surgeon and lecturer in surgery at Bart's for twenty years, had to pay heavy damages for breaking a united callus in a patient's tibia and extending the leg with an appliance which one witness described as "a heavy steel thing with teeth." The judge said, "For anything that appears to the Court, this was the first experiment made with this new instrument, and if it was, it was a rash action."

Nowadays, the courts recognize that knowledge of science is progressive and advances daily. They do not hold that a new kind of treatment is malpraxis in itself, but they require that the surgeon shall explain to the patient clearly what he intends to do and why, and the extra risk it entails. He should do so even if the prospect of cure is much greater and the old method was merely a palliative. The courts will also ask why the new treatment was applied. If it were a mere ungrounded experiment, the judge might hint to the jury that it would be right to consider the surgeon negligent. If the patient suffered grave injury and the surgeon had shown a certain degree of culpable levity in his experiment, he might have to face a criminal prosecution. But if the method has been carefully thought out and proceeds logically from scientific research, the surgeon is justified in using it even for the first time.

X-rays.-Many surgeons have got into trouble through not having an injured part radiographed. Every medical man knows that the value of a radiograph may in practice be very small, but every medical man ought to know that the value of a radiograph in the law courts is very high indeed. Every surgeon should take it as a rule of law that to omit to take an X-ray in case of a bone injury is in itself an act of negligence. This seems to be the attitude of every jury now-a-days, and the safest thing to do is to respect it. If the patient objects, the surgeon should insist on his putting the objection in writing and signing it or, failing this, should himself make a note of the refusal, or write a letter to the patient repeating his advice. Time and again patients have objected verbally and afterwards flatly denied doing anything of the sort when they thought that there were damages to be had.

The following instance is from general rather than surgical practice, but it illustrates the point, and the victim was, in fact, a young woman surgeon, well aware of the importance of the X-ray, both surgically and legally. She lives opposite a girls' day school, and a girl was brought over to her one morning for first aid to a finger which had been injured by a chance knock while running along a passage. There was no deformity, and the surgeon advised the girl in the presence of the mistress that it was impossible to tell, without an X-ray, whether a phalanx had been broken or not, but that the treatment in either case would be the same. She then splinted the hand and expected that the girl would be seen by her parents' doctor at home. Three or four days later, however, the girl was brought to her by the mistress once more. Movement in the finger was perfect but much more bruising had come out. This was the point at which, of course, the surgeon. should have made it quite clear either that the girl must go to her own doctor for care or else that she must have an X-ray. As, however,

1 Slater v. Baker, \& c., 2 Wils. 359. 
all seemed going perfectly well, she removed the splint, and warned the girl to be careful of her hand and to keep her arm in a sling. Later on the girl knocked the finger again, and then went to the home doctor, who had an X-ray taken and found a fracture. The parents tried to bring an action against the surgeon, but the case was settled by the Protection Society.

\section{Vicarious Liability.}

Besides being made responsible for his own negligence, a surgeon may sometimes be held liable for the negligence of his assistants. Broadly speaking, the rule of law is that a man is liable for injury caused by anyone whose action he is in a position to control. A long series of decisions has, however, restricted the liability of the surgeon for other people's mistakes. For instance, a surgeon is not liable for the negligence of a nurse who is carrying out in his absence under his orders some task which it is quite proper he should delegate to her. It may be another matter if he has reason to believe that she is incompetent, or if he gives her something to do which, considering all the the facts of the case, is beyond her powers. But in ordinary practice he is not liable. In the case of Perionowsky v. Freeman, ${ }^{1}$ heard about seventy years ago in the High Court, a former patient sued two surgeons of St. George's Hospital. They had ordered him a hip bath, and he said that the nurses had made the water much too hot and had held him in it in spite of his screams and struggles, so that he was badly scalded. The court obviously did not believe him, but the judge said quite enough to show that he lost his action because the surgeons were not there at the time, and had every right to delegate the duty to the nurses.

The surgeon operates with a team of skilled assistants. His responsibility for the negligence of these assistants has not yet been definitely settled at law. In the case of Hillyer v. St. Bartholomew's Hospital (I908, 2 K.B. 820), a patient sued the hospital because one arm was burnt and the other crushed during an operation. Lord Justice Farwell, a member of the Court of Appeal, expressed the opinion that the hospital governors were not responsible because when the doors of the operating theatre had closed the surgeon was in supreme command. The Court of Appeal was trying the question of whether the hospital was liable and was not concerned with the liability of the surgeon. These remarks are therefore only obiler dicta and do not establish any principle of law. Far too much has been made of them in argument and they have never been tested in a case. It is a much more certain rule that if a man employs another to do a job which requires special skill and which he himself is not competent to supervise, he is not responsible if that job is done negligently, but only for choosing in the first place a competent man. The great majority of both surgical and legal opinion agrees that the assistant surgeon, the anæsthetist, the theatre sister and the other members of the operation team are skilled assistants doing their own particular job.

All surgeons know that the senior surgeon at an operation knows the job of every one of the team-with the possible exception of the anæsthetist-better than the assistant does himself or herself. The only person whom he is possibly not competent to supervise is the anæsthetist, and for this reason it is practically certain that he would not be 
held responsible for the anæsthetist's misdoings unless he had himself selected him without good reason for thinking him competent. To each and all of the other members he can at any stage of the operation say : "You are doing that wrong." To that extent the law might say that he had control of his assistants and was therefore responsible for their misdoings. But in practice he has his own job to do all the time, and it requires a very high degree of concentration : so high a degree that if he is to serve the best interests of the patient he has very little attention to spare for the actions of his assistants. On the common sense of the matter, he ought to be allowed to rely on the competence of his assistants at least during those parts of the operation where he needs all his attention for his own work.

Foreign Bodies Left in the.Abdomen.-The question of the surgeon's responsibility for his assistants chiefly arises when by some mischance an instrument or swab has been sewn up in the patient. I believe that the practice nearly everywhere is that before the surgeon closes the wound he asks the question: "Is everything out, sister ?" and the theatre sister's word is taken for it. It is impossible for the surgeon to make a search to see that all the swabs and small instruments are out, and to attempt to do so would be very bad for the patient.

As yet, the law is not certain whether to free the surgeon from responsibility for the count of the theatre sister or not. It is fairly certain that when something is left in the wound someone has to pay damages unless there is a very good excuse. In South Africa the Courts have definitely ruled that a surgeon can rely on the count of the theatre sister, and that to leave an instrument or swab in the abdomen is not in itself proof of negligence but has to be taken with all the circumstances. The case is called $V a n W_{y k}$ v. Lewis (1924, Appellate Division 438). The judges strongly backed up the surgical side, and I recommend anyone interested in this problem to read the case through. In this country we get out of it by leaving the jury to decide as a matter of fact on all the evidence whether the surgeon at the particular operation was negligent or not.

In the case of Crotch v. Miles, which the Lord Chief Justice tried in 1930,' a former patient sued Mr. Ernest Miles for leaving a pair of forceps in her abdomen ten years before. The jury found that the forceps had been left in at a later operation which the patient had had in France, and every suggestion of negligence against Mr. Miles was completely disproved. But in his summing up Lord Hewart had to direct the jury to consider, if they decided that the forceps had been left in at Mr. Miles' operation, whether Mr. Miles had been negligent. His words show fairly clearly the attitude of one of the finest common lawyers of to-day towards the question of whether a surgeon can rely on his theatre sister. He said

"You may think that it is right to draw a distinction between what is done in the course of the operation and what is done immediately at its close. It may well be that in the actual course of the operation, while the surgeon is cutting and opening and attending to his surgical task, it is not to be expected nor desired that he should be busying his mind with the counting of instruments or swabs or with the question of whether a swab or instrument is missing. But you may thinkj that other considerations apply at the close of the surgery itself. It may well be that any delay might be highly prejudicial if it occurred before the body

1 The Lancet, 1930, i, 706. 
of the patient was stitched up, but after that you may think that before the surgeon departs it is reasonable that he should personally satisfy himself that the number is correct, and that there is nothing missing. Mr. Mites says that he does that. Sir Hugh Rigby said that it is not usual, and he himself does not do it."

"You have to put yourselves at November, 1920. Was it in November, 1920, part of the duty of the surgeon personally to count the instruments and satisfy himself that the number was correct, or was he entitled to say that there was present a skilled theatre sister, that this was her job, and that he was entitled to act upon her report ? She is not his servant, she is one of the team. We can all make mistakes. I suppose it is quite conceivable that somebody in an individual case might miscuunt a certain instrument. You have to address your minds to this question: suppose the theatre sister did miscount and thought there were six of these instruments when there were only five, is the defendant responsible for that happening? Is it a breach of duty on his part that the theatre sister made that mistake? You may think it is linked up with the question as to what he did afterwards."

In other words, the Lord Chief Justice thought that the surgeon was entitled to close up on the theatre sister's word, but ought to count the instruments himself afterwards to make sure that all were there. Whether the same holds good for swabs is doubtful. The South African case, where the judges were so strongly in favour of the surgeon, concerned a swab, and their remarks ought not to be stretched to cover anything but swabs. In any event, a South African decision is not binding in an English court. It is possible to argue that, whereas the instruments are very often the property of the surgeon and he should ultimately account for them, the swabs are supplied by the hospital management and handed one by one to the surgeon as he wants them; the responsibility for counting them might therefore reasonably be said to rest with the theatre sister. Mr. Rowland Segar, ${ }^{1}$ discussing two cases of swabs left in, said that both operations were acute emergencies, both swabs were very large and neither was provided with a tape. He suggests that swabs should have small discs of lead in them to render them opaque to X-rays.

Sometimes an emergency will excuse the leaving-in of a foreign body. When the anæsthetist says that the surgeon must sew the patient up at once and get him off the table there is obviously no time to count sixty or seventy instruments first. In one case of this kind a pair of forceps was left in and the count showed it missing. It was found by X-rays in the abdomen, but the patient died after the second operation for its removal. The advisers of the widow argued that the mere leaving of it in was a proof of negligence, but the jury found that the surgeon had done all he could (Charlesworth v. Graham and Love; Chester Assizes, Brit. Med. Jour., 1928, i, 328).

\section{Groundless Actions.}

As the law stands at present, any patient who likes can bring an action against a surgeon for negligence on the flimsiest pretext. Sometimes the real reason is to avoid having to pay a fee; sometimes it is the hope of getting substantial compensation for a 
slight or non-existent injury: sometimes the patient believes that he has a genuine grievance, although the law is against him. Very many cases are commenced against surgeons and abandoned- $a$ few in the middle of the trial and the majority when it becomes apparent that the complaint will be vigorously opposed. If the surgeon has to go to court he may win his case, but he is put to great expense, severe worry and the loss of much valuable time. Very often, although he gets an order for the complainant to pay his costs, the complainant has no money. For this reason it is worth a great deal to stop the case earlier if possible. This is one of the many uses of a defence society. For every case that has come into court fifty must have been threatened, and then dropped when the defence society announced that it proposed to fight. If the patient chooses to go into court in defiance of the society the surgeon will have his case conducted by the best possible men of law, and if he loses, nevertheless the society will indemnify him. Speaking as a lawyer who has studied the risks to which surgeons are exposed and the grave uncertainty of the law concerning them, I cannot understand how any surgeon can abstain from this simple and effective measure of self-preservation.

\title{
PSYCHIATRIC PROBLEMS IN GENERAL PRACTICE.
}

\author{
BY THOMAS TENNENT, M.D., M.R.C.P. \\ Deputy Medical Superintendent, Maudsley Hospital; Physician in Psychological Medicine, Miller \\ General Hospital.
}

Mental disorders constitute some of the most difficult problems with which the physician is confronted. Varieties of these have been recognized from time immemorial but the attitude adopted towards them has varied according to the current beliefs as to the causation. Historians trace references back to the time of the ancient Greeks, at which period the treatment appears to have been in the hands of the physicians. Hippocrates, we find, believed that the brain was the seat of the mind, and that mental disorders originated from a natural cause similar to any other illness. At a later period, those suffering from mental illness came to be regarded as bewitched or possessed of evil spirits, and their treatment passed into the hands of religious bodies. We find that the first hospital in England, for the care of the mentally disordered dates back to the beginning of the fifteenth century. Until comparatively recently such disorders were treated purely from the physical point of view and medication was directed to that end. Throughout this period psychiatrists were content to restrict their interests and activities to patients suffering from the major psychoses, confined within the walls of their hospitals. Fortunately this attitude has undergone a radical change and psychiatrists no longer concern themselves exclusively with the advanced stages of the grosser forms of mental illness but are grappling with such patients in the early stages of their illness and also with that large group of minor disorders, the psychoneuroses.

The problem is an enormous one. According to the Annual Report of the Board of Control there were on January I, 1932, 146,696 patients under treatment for mental disorders in England and Wales. During the past five years the average increase has been $\mathbf{I}, 855$. In monetary values the cost alone to the country is $€ 7,000,000$ per annum. 